\title{
The effect of sintered dicalcium pyrophosphate on osteoclast metabolism: An ultrastructural study
}

\author{
Jui-Sheng Sun, ${ }^{1}$ Yi-Chau Huang, ${ }^{2}$ Feng-Huei Lin, ${ }^{2}$ Li-Ting Chen ${ }^{1}$ \\ ${ }^{1}$ Department of Orthopedic Surgery, National Taiwan University Hospital, No. 7, Chung-Shan South Road, \\ Taipei, Taiwan, ROC \\ ${ }^{2}$ Institute of Biomedical Engineering, National Taiwan University, Taipei, Taiwan, ROC
}

Received 9 August 2001; revised 22 April 2002; accepted 28 May 2002

\begin{abstract}
Sintered dicalcium pyrophosphate (SDCP), a synthetic compound, has proved to be both bioabsorbable and biocompatible in vivo. Recent work in our institute also has demonstrated that the ingestion of SDCP can increase bone mass in the ovariectomized rat. In this study, we used an in vitro cell culture model to investigate the ultrastructural changes and fate of osteoclasts induced by SDCP. Quantitative evaluation of osteoblasts and osteoclasts after administration of SDCP was performed. We studied immunohistochemical and ultrastructural features of osteoclasts undergoing apoptosis. The results showed that at $10^{-4} \mathrm{M}$ SDCP, the osteoblast cell count increased significantly, whereas the osteoclast population decreased significantly. Apoptosis of the osteoclast population was well demonstrated by immunohistochemical study. Ultrastructural
\end{abstract}

study showed that the Golgi apparatus was degraded or dispersed in the cytoplasm. Later, osteoclasts revealed pyknotic nuclei showing condensation and margination of heterochromatins and DNA fragmentation, which are typical features of apoptosis. In addition, disruption of nuclear envelopes leading to leakage of nuclear contents into the cytoplasm was observed in the late stage of apoptosis. In conclusion, SDCP-induced apoptosis of osteoclasts was characterized by ultrastructural changes of the nucleus accompanied by degradation of cellular organelles. (c) 2003 Wiley Periodicals, Inc. J Biomed Mater Res 64A: 616-621, 2003

Key words: osteoclast; apoptosis; sintered dicalcium pyrophophate; ultrastructure

\section{INTRODUCTION}

Osteoporosis, a major health care problem of aging populations, is characterized by an increase in bone resorption relative to bone formation. ${ }^{1}$ The progressive decrease in bone mass leads to increased susceptibility to fractures, resulting in substantial morbidity and mortality. ${ }^{2}$ Although there are several risk factors for fractures, reduced bone mineral density is the strongest predictor. ${ }^{3}$ Thus, the ultimate goal of pharmacologic treatment in osteoporosis is to reduce the risk of fractures by increasing bone mass of normal quality.

Osteoclasts play a key role in bone resorption and remodeling in conjunction with osteoblasts. Multinucleated osteoclasts are derived from mononuclear pre-

Correspondence to: Feng-Huei Lin; e-mail: double@ha.mc. ntu.edu.tw or Jui-Sheng Sun; e-mail: drjssun@ccms.ntu. edu.tw

Contract grant sponsor: National Science Council, ROC.

(C) 2003 Wiley Periodicals, Inc. osteoclasts via cell fusion. Although the formation of osteoclasts has been well documented by many investigators, ${ }^{4,5}$ it is rare to find dying osteoclasts in normal conditions. Hughes et al. demonstrated that an injection of bisphosphonates efficiently causes apoptosis of osteoclasts. ${ }^{6}$ Bisphosphonates are synthetic pyrophosphate analogs that can inhibit osteoclastic bone resorption. ${ }^{7-9}$ They are effective for the treatment of humoral hypercalcemia of malignancies, local osteolytic hypercalcemia, Paget's disease, and osteoporosis. ${ }^{7,10,11}$ Bisphosphonates bind tightly to calcified bone matrix, then inhibit the differentiation of osteoclasts ${ }^{12}$ and osteoclastic bone resorption mediated by osteoblasts, ${ }^{13}$ or the activity of macrophage ${ }^{14}$ Later, apoptosis of osteoclasts induced by bisphosphonate was demonstrated by Ito et al. ${ }^{15}$

In vivo, sintered dicalcium phyrphosphate (SDCP), a synthetic compound, has proven to be quite biocompatible to bone tissue. ${ }^{16}$ In vitro, SDCP has proven to be more biocompatible than hydroxyapatite. ${ }^{17}$ As a pyrophosphate analog, SDCP should be useful in clinical settings characterized by abnormal bone resorption, such as osteoporosis. ${ }^{18}$ Recent work in our institute demonstrated that the ingestion of either bis- 
phosphonate or SDCP decreases the bony porosity and increases bone mineral contents in the long bones of ovariectomized rats. ${ }^{19}$ In this study, we used an in vitro cell culture model to investigate ultrastructural changes and the fate of osteoclasts undergoing apoptosis induced by SDCP.

\section{MATERIALS AND METHODS}

\section{Preparation of sintered $\beta$-dicalcium pyrophosphate solutions}

The powder of sintered $\beta$-dicalcium pyrophosphate $(\beta$ DCP) was prepared as previously described. ${ }^{16}$ In short, $\beta$-DCP powder ( $\beta$-DCP: $\mathrm{Ca}_{2} \mathrm{P}_{2} \mathrm{O}_{7}$; Sigma, St. Louis, MO) was mixed with $5 \mathrm{wt} \% \mathrm{Na}_{4} \mathrm{P}_{2} \mathrm{O}_{7} \cdot 10 \mathrm{H}_{2} \mathrm{O}$ in water and dried at $70^{\circ} \mathrm{C}$ for 3 days. The well-mixed and dried cake was ground and sieved to obtain 40-60 mesh particles. The sieved particles were placed in a platinum crucible and heated up to $930^{\circ} \mathrm{C}$ at a rate of $3^{\circ} \mathrm{C} / \mathrm{min}$ in a conventional $\mathrm{Ni}-\mathrm{Cr}$ coiled furnace and then maintained in air for $1 \mathrm{~h}$ after the $930^{\circ} \mathrm{C}$ sintering temperature was obtained. The SDCP obtained was dissolved by $\mathrm{HCl}$ and then diluted into different concentration solutions by culture media used in the bone cell culture. In the first part of this study, the effects of various concentrations of SDCP on bone cell activities were evaluated by tetrazolium (MTT) assay as described below. Four different concentrations $\left(1.0 \times 10^{-2} \mathrm{M}, 1.0 \times 10^{-3} \mathrm{M}, 1.0 \times\right.$ $10^{-4} \mathrm{M}, 1.0 \times 10^{-5} \mathrm{M}$ ) were tested for periods of 1,3 , and 7 days.

\section{Osteoblast/osteoclast coculture (mixed bone cells culture) and osteoblast culture}

The rat alveolar mononuclear cells-calvarias osteoblasts coculture system used in this study was the same as previously described..$^{20}$ Newborn Wistar rats (3-5 days old) were obtained from the laboratory center of the Medical College, National Taiwan University. Primary osteoblast cells were prepared from newborn rat calvarias. For the mixed bone cells culture, osteoblast cells $\left(1 \times 10^{4}\right.$ cells / well $)$ and alveolar mononuclear cells $\left(7.5 \times 10^{5}\right.$ cells /well) were cocultured in 6-well plates for 6 days in Dulbecco's modified Eagle's medium (DMEM) containing 10\% fetal calf serum (FCS; Gibco $\mathrm{BRL}$, Rockville, MD), in the presence of $10 \mathrm{n} M 1 \alpha$, $25(\mathrm{OH})_{2} \mathrm{D}_{3}$. Penicillin $\mathrm{G}$ sodium 100 units $/ \mathrm{mL}$ and streptomycin $100 \mathrm{mg} / \mathrm{mL}$ (Gibco BRL, Rockville, MD) were added. The culture dishes were incubated at $37^{\circ} \mathrm{C}$ in an atmosphere supplemented with $5 \% \mathrm{CO}_{2}$. After 6 days' culture and observation of the differentiated osteoclasts, various concentrations of SDCP were added. For the osteoblast culture, osteoblast cells $\left(1 \times 10^{5}\right.$ cells / well $)$ were cultured for 2 days to facilitate their attachment, then subjected to preparation and management similar to that of the mixed bone cells culture, as described above.

\section{Colorimetric MTT (tetrazolium) assay for cell viability ${ }^{21}$}

The mitochondrial activity of the bone cells after exposure to various concentrations of SDCP was determined by colorimetric assay, which detects the conversion of 3-(4,5dimethylthiazolyl-2)-2,5-diphenyltetrazolium bromide (MTT, Sigma catalog no. M2128; Sigma Co., St. Louis, MO) to formazan. For the assay, $2.5 \times 10^{4}$ cells per well were incubated $\left(5 \% \mathrm{CO}_{2}, 37^{\circ} \mathrm{C}\right)$ in the presence of various concentration of SDCP. After predetermined time intervals, the supernatant was removed, $100 \mu \mathrm{L} /$ well of MTT solution (1 $\mathrm{mg} / \mathrm{mL}$ in test medium) was added, and the wells were incubated at $37^{\circ} \mathrm{C}$ for $4 \mathrm{~h}$ to allow the formation of formazan crystals. Again, the supernatant was removed and acidisopropanol $(100 \mu \mathrm{L} 0.04 \mathrm{~N} \mathrm{HCl}$ in isopropanol) was added to all wells and mixed thoroughly to dissolve the dark-blue crystals. After all crystals were dissolved, the plates were read on a Micro Elisa reader (Emax Science Corp., Sunnyvale, CA), with a test wavelength of $570 \mathrm{~nm}$ against a reference wavelength of $690 \mathrm{~nm}$. Plates were normally read within $1 \mathrm{~h}$ after adding the isopropanol.

\section{Statistical analysis}

In this study, all experiments were performed in a paired pattern and replicated 10 times. The differences between various tested conditions were evaluated by the paired $t$ test. The level of statistical significance is defined as $P<0.05$.

\section{Identification of fragmented DNA by TUNEL staining}

Detection of apoptosis in bone cells after SDCP treatment was performed by the immunohistochemical methods described by Sgonc et al. ${ }^{22}$ For the assay, $1.0 \times 10^{5}$ cells $/ \mathrm{mL}$ in $9.4 \mathrm{~cm}^{2}$ culture dishes were incubated in the presence of SDCP. After various time intervals, the supernatants were removed, cell samples were fixed with paraformaldehyde solution [ $4 \%$ in phosphate-buffered saline (PBS), $\mathrm{pH} 7.4$ ] for $30 \mathrm{~min}$ at room temperature. The endogenous peroxidase was blocked by $0.3 \% \mathrm{H}_{2} \mathrm{O}_{2}$ then permeated with $0.1 \%$ Triton $\mathrm{X}-100$ in $0.1 \%$ sodium citrate (Boehringer Mannheim, Mannheim, Germany) for $2 \mathrm{~min}$ on ice $\left(4^{\circ} \mathrm{C}\right)$. The DNA strand breaks in bone cells were then fluorescence-labeled by $100 \mu \mathrm{L}$ TUNEL (TdT-mediated dUTP nick end labeling) reaction mixture (Boehringer Mannheim, Mannheim, Germany) and incubated for $60 \mathrm{~min}$. Antifluorescence antibody conjugated with POD (peroxidase; Boehringer Mannheim, Mannheim, Germany) was added and then incubated with samples for $30 \mathrm{~min}$. 3,3'-Diaminobenzidine (DAB)-substrate solution was added and incubated for $10 \mathrm{~min}$. Samples were then analyzed under light microscope.

\section{Ultrastructural study}

For transmission electron microscopy (TEM), the bone cells were trypsinized, diluted with PBS solution, and cen- 
trifuged; then the cell pellets were fixed with $3 \%$ phosphatebuffered formaldehyde $(\mathrm{pH} 7.4)$ for 1.5 hour at $4^{\circ} \mathrm{C}$. The specimens were then postfixed with an aqueous solution of $1 \% \mathrm{OsO}_{4}$ and $1.5 \%$ ferrocyanide for $3 \mathrm{~h}$ at $4{ }^{\circ} \mathrm{C}$. The specimens were dehydrated in acetone and embedded in PolyBed (Polyscience, Inc., Warrington, PA). Ultrathin sections stained with uranyl acetate and lead citrate were examined under a Zeiss EM EM109 electron microscope (Zeiss Co., Ltd., Germany) operated at $80 \mathrm{kV}$.

\section{RESULTS}

\section{Quantitative analysis of osteoblasts and osteoclasts}

MTT is a pale-yellow substrate that produces a dark-blue formazan product when incubated with living cells. The MTT ring is cleaved in active mitochondria, and the reaction occurs only in living cells. ${ }^{21}$ Figure 1 shows the effect of various concentrations of SDCP on bone cells viability measured by MTT assay. When osteoblast cells were cultured with $10^{-2}$ or $10^{-3}$ $M$ SDCP, there was a significant decrease in the formation of formazan, whereas in the $10^{-4}$ or $10^{-5} \mathrm{M}$ concentration of SDCP, the formation of formazan was significantly increased, and this effect persisted till the end of 3 days' culture (Fig. 1). At the $10^{-4} M$ concentration of SDCP, the beneficial effect on the osteoblasts persisted till the end of 7 days' culture, although it did not attain the significant level (Fig. 1). When osteoclast cells were cultured with $10^{-2}, 10^{-3}$, or $10^{-4} \mathrm{M}$ concentrations of SDCP, mixed bone cell populations significantly decreased, whereas at the $10^{-5} \mathrm{M}$ concentrations of SDCP, no statistically significant change was observed (Fig. 1). The $10^{-4} M$ concentration of SDCP had a beneficial effect on the osteoblast population, whereas its effect on osteoclast formation was deleterious. In this study, we selected the concentration of $10^{-4} \mathrm{M}$ SDCP for the further evaluation of mixed bone cell activities.

\section{Immunohistochemical identification of apoptosis}

For the osteoclasts in control groups, there was no morphologic change at any stage of this study (Fig. 2, Control: 1D, 3D, 7D). On the other hand, osteoclasts undergoing apoptosis after $10^{-4} \mathrm{M}$ SDCP treatment were quite obvious in the study of in situ immunohistochemical stain for apoptosis. Cellular changes of apoptotic osteoclasts increased in severity with time. After 1 day SDCP treatment, apoptosis was detected in the osteoclasts clusters by showing dense stain in the experimental groups. (Fig. 2, Experiment: 1D). After 3 days treatment of SDCP, apoptosis of osteoclasts was even more significant, as manifested by the pyknotic changes in the nucleus of the osteoclasts gi-

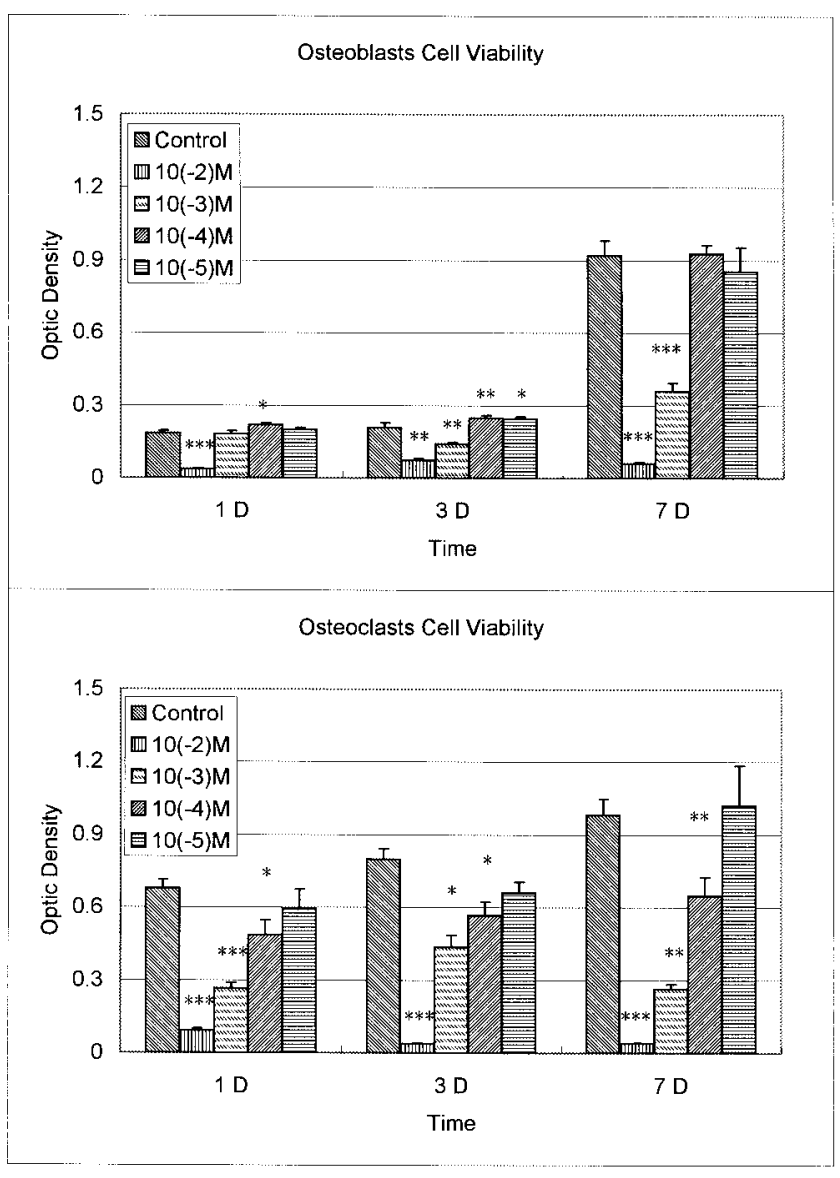

Figure 1. Effect of various concentration of SDCP on bone cells viability measured by MTT assay $(n=10)$. When osteoblast cells cultured with $10^{-2}$ or $10^{-3} M$ concentrations of $\mathrm{SDCP}$, the osteoblast cell count was significantly decreased, whereas in the $10^{-4}$ or $10^{-5} \mathrm{M}$ concentrations of SDCP, the osteoblast cell count increased significantly, and this effect persisted till the end of 3 days' culture. At the $10^{-4} \mathrm{M}$ concentration of SDCP, the beneficial effect on the osteoblasts persisted till the end of 7 days' culture, although it did not attain the significant level. When osteoclast cells were cultured with $10^{-2}, 10^{-3}$, or $10^{-4} \mathrm{M}$ concentrations of SDCP, there was a significant decrease in the cell count of osteoclasts, whereas at the $10^{-5} \mathrm{M}$ SDCP concentration, there was no statistical change in the cell count of osteoclasts. ${ }^{*} P<0.05$, ${ }^{* *} P<0.005,{ }^{* * *} P<0.0005$.

ant cells (Fig. 2, Experiment: 3D). After 7 days SDCP treatment, there was loss of cellularity in the center of osteoclast giant cells, and some residual apoptotic cells with pyknotic nucleus were visible. However, osteoblasts population surrounding the apoptotic osteoclast giant cells was relatively preserved (Fig. 2, Experiment: 7D).

\section{Ultrastructural changes observed in electron microscopic examinations}

On electron microscopic examination, more than 50 osteoclasts were studied at each stage. In the early 

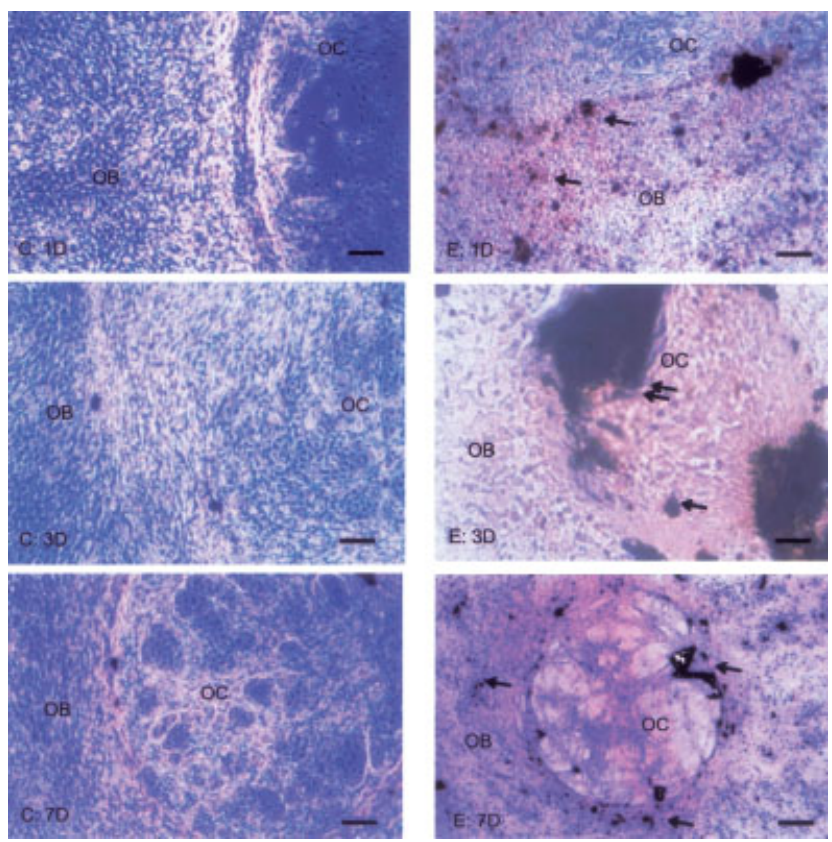

Figure 2. The in situ immunohistochemical stain for apoptosis after $10^{-4} M$ SDCP treatment. 1D: After 1 day's SDCP treatment on bone cells, apoptosis of the osteoclasts was detected in the clusters by exhibiting dense stain in the samples. 3D: The apoptosis of osteoclasts were even more significant after 3 days' SDCP treatment, as manifested by the pyknotic changes in the nucleus of the osteoclast giant cells. 7D: After 7 days' SDCP treatment, there was loss of cellularity in the center of osteoclast giant cells and some residual apoptotic cells with pyknotic nucleus visible, but the surrounding osteoblasts populations were relatively preserved. (C: Control; E: Experiment; O.B.: Osteoblasts; O.C. Osteoclasts; Arrow: Apoptic cell; Double arrows: Pynotic osteoclasts giant cells; Bar $=100 \mu \mathrm{m}$ ). [Color figure can be viewed in the online issue, which is available at www. interscience.wiley.com.]

stage, the Golgi apparatus of osteoclasts was degraded, resulting in accumulation of small vesicles in the area of Golgi apparatus, or widely dispersed within the cytoplasm [Fig. 3(B)]. However, nuclear condensation was not obvious at this stage [Fig. 3(B)]. These features were observed in most osteoclasts undergoing apoptosis.

At 3 days, osteoclasts exhibited numerous pyknotic nuclei containing condensed heterochromatins, while these condensed heterochromatins were often against the marginated nuclear envelope at this stage [Fig. $3(\mathrm{C})$ ]. Granular structures indicative of chromatin condensation also appeared in the pyknotic nuclei of apoptotic osteoclasts [Fig. 3(C)]. The Golgi apparatus was not observed, and there were many vesicles in the cytoplasm. Plasma membrane of these osteoclasts were often convoluted to give rise to membranebound apoptotic bodies [Fig. 3(D)].

The pyknotic nuclei of osteoclasts in the late stage of apoptosis displayed enlargement of the nuclear envelope resulting from dissociation of the outer and inner
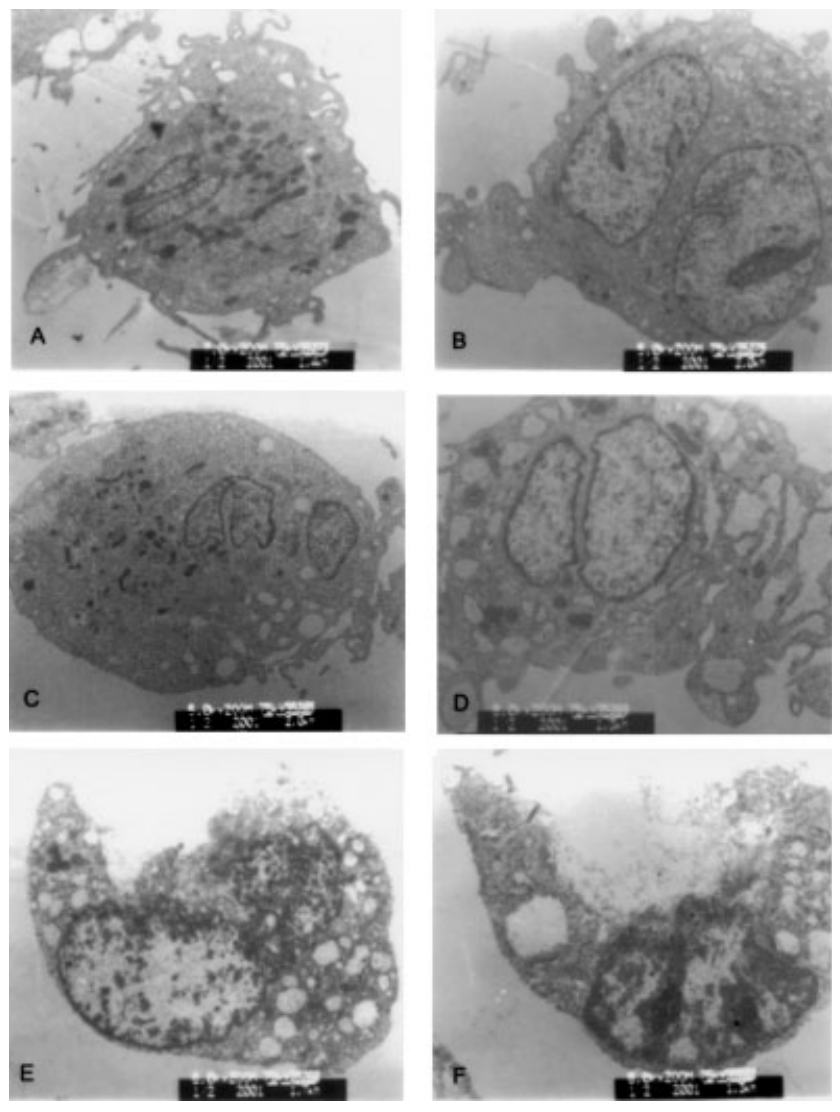

Figure 3. Ultrastructural changes of osteoclasts apoptosis in the presence of $10^{-4} \mathrm{M}$ concentrations of SDCP: (A) Normal osteoclast of control sample. (B) In osteoclasts at day 1 of apoptosis, the Golgi apparatus was degraded, resulting in accumulation of small vesicles in the area of Golgi apparatus or dispersed in the cytoplasm. (C) At 3 days, osteoclasts later exhibited typical features of apoptosis, with numerous pyknotic nuclei containing condensed heterochromatins, which were often marginated against the nuclear envelope. (D) The Golgi apparatus was not observed, and there were many vesicles in the cytoplasm. These osteoclasts were often convoluted, giving rise to membrane-bound apoptotic bodies on day 3. (E) The pyknotic nuclei of osteoclasts on day 7 of apoptosis displayed enlargement of the nuclear envelope as a result of dissociation of the outer and inner nuclear membranes, with accumulation of amorphous material between them. (F) In most severely apoptotic osteoclasts on day 7, some nuclei were disrupted, as evidenced by the rupture of the nuclear envelope, leading to leakage of nuclear components in the cytoplasm.

nuclear membranes, with accumulation of amorphous material between them. The outer membranes of closely apposed nuclei were fused, and the amorphous material had accumulated between the two nuclei [Fig. 3(E)]. In some instances, the inner membranes of neighboring nuclei were juxtaposed. Irregularly shaped osmiophilic granules were observed in association with condensed heterochromatins of the juxtaposed nuclei [Fig. 3(E)]. Some nuclei were disrupted, as evidenced by the rupture of the nuclear envelope, leading to leakage of nuclear components in 
the cytoplasm [Fig. 3(F)]. These alterations of nuclear structures were observed in most of the severely apoptotic osteoclasts.

\section{DISCUSSION}

Osteoporosis is a major health care problem of aging populations. For the evaluation of agents intended to prevent and/or treat postmenopausal osteoporosis, the adult ovariectomized rat is a convenient and reliable experimental model. In the pilot study at our institute, we have proved that SDCP can increase bone mass in the ovariectomized rat. ${ }^{19}$ In vivo, it is difficult to examine the reaction of a specific cell to substrate because numerous cell populations and chemical factors are involved in this experimental model. In order to determine the sequences of events and the parameters influencing the interactive process, the model of a cell culture in the presence of specific substrate is of great importance. In this study, we used an in vitro bone cell culture model to investigate the ultrastructural changes and fate of osteoclasts after SDCP administration.

All bisphosphonates have a high affinity for hydroxyapatite and are resistant to metabolism by endogenous phosphatases. ${ }^{7,23}$ SDCPs, unlike bisphosphonates, are bioabsorbable and can be metabolized by endogenous phosphatases. ${ }^{16}$ In this study, we found that when bone cells were cultured with $10^{-4} \mathrm{M}$ SDCP, there were differential effects on the osteoblasts and osteoclasts. The osteoblasts population increased significantly, whereas osteoclasts cell counts decreased significantly (Fig. 1). In this study, we selected the concentration $10^{-4} \mathrm{M}$ SDCP for the further osteoclasts activities evaluation. At a $10^{-4} \mathrm{M}$ concentration of SDCP administration, the osteoclasts showed definite evidence of apoptosis, and the cellular changes of apoptotic osteoclasts increased in severity with time (Fig. 2). The decrease of osteoclasts may be ascribed mainly to apoptosis resulting from incorporation of SDCP. ${ }^{24,25}$

The clinically useful bisphosphonates are synthetic analogues of inorganic pyrophosphate, an endogenous regulator of bone turnover that has been found to inhibit in vitro bone resorption and mineralization. ${ }^{7}$ In clinical medicine, treatment with bisphosphonates can normalize the rate of bone turnover by the inhibition of bone resorption. ${ }^{26}$ Later, bisphosphonate was proved to induce the apoptosis of osteoclasts. ${ }^{15}$ Cells undergoing apoptosis are characterized by accumulation of nuclear chromatin resulting from fragmentation of genomic DNA, without any alteration of cellular organelles. ${ }^{27,28}$ Recent studies have also shown that various ultrastructural changes of cellular organelles occur depending on cell type and function. ${ }^{28}$

After SDCP administration, most osteoclasts are subjected to apoptosis and manifest ultrastructure changes that are different from those of other cells, because they are specialized bone-resorbing cells. Unlike normal osteoclasts [Fig. 3(A)], degradation of the Golgi apparatus resulting in vesiculation of osteoclasts appeared soon after SDCP administration [Fig. 3(B)]. The alteration of cellular organelles occurred before nuclear pyknosis. The nuclear condensation was not obvious in these osteoclasts in the early phase of apoptosis [Fig. 3(B)]; osteoclasts showing nuclear pyknosis associated with condensation and margination of chromatins appeared on day 3 [Fig. 3(C)]. The findings are consistent with the reports of Hughes et al. and others, ${ }^{6,29,30}$ in which granular structures were observed in nuclei exhibiting nuclear condensation. They may be the initial alteration leading to chromatin condensation in cells undergoing apoptosis. The nuclear envelope of pyknotic nuclei became enlarged and finally fused [Figs. 3(D) and 3(E)]. Some nuclei were disrupted, as evidenced by rupture of the nuclear envelope, leading to leakage of nuclear components into the cytoplasm [Fig. 3(F)]. They may be the structures that facilitate diffusion of nuclear components. It is likely that they are products derived secondarily from condensed heterochromatin. These alterations of nuclear structures were observed in most of the severely apoptotic osteoclasts. ${ }^{15}$ Thus, the changes induced by SDCP administration were the results of apoptosis.

In summary, SDCP, unlike bisphosphonate, has a high affinity to osteoblasts. It induced osteoclast apoptosis characterized by degradation of the Golgi apparatus, followed by nuclear pyknosis associated with condensation and margination of chromatin, and formation of apoptotic bodies. Enlargement and fusion of the nuclear envelope were characteristics of apoptosis of osteoclasts. Because apoptotic osteoclasts induced by SDCP resemble dying or dead osteoclasts seen in a physiologic condition, osteoclasts may be subjected to cell death by apoptosis.

\section{References}

1. Riggs BL, Melton LJ III. The prevention and treatment of osteoporosis. N Engl J Med 1992;327:620-627.

2. Burger H, van Daele PL, Algra D, Hofman A, Grobbee DE, Schutte HE, Birkenhager JC, Pols HA. Vertebral deformities as predictors of non-vertebral fractures. Br Med J 1994;309:991992.

3. Leichter I, Margulies JY, Weinreb A, Mizrahi J, Robin GC, Conforty B, Makin M, Bloch B. The relationship between bone density, mineral content, and mechanical strength in the femoral neck. Clin Orthop 1982;163:272-281.

4. Rodan GA, Martin TJ. Role of osteoblasts in hormonal control of bone resorption: A hypothesis. Calcif Tissue Int 1981;33:349351.

5. Takahashi N, Yamana H, Yoshiki S, Roodman GD, Mundy GR, Jones SJ, Suda T. Osteoclast-like cell formation and its regula- 
tion by osteotropic hormones in mouse bone marrow cultures. Endocrinology 1988;122:1373-1382.

6. Hughes DE, Wright KR, UY HL, Sasaki A, Yoneda T, Roodman GD, Mundy GR, Boyce BF. Bisphosphonates promote apoptosis in murine osteoclasts in vitro and in vivo. J Bone Miner Res 1995;10:1478-1487.

7. Fleisch H. Bisphosphonates: Pharmacology and use in the treatment of tumour-induced hypercalcaemic and metastatic bone disease. Drugs 1991;42:919-944.

8. Ott SM. Clinical effects of bisphosphonates in involutional osteoporosis. J Bone Miner Res 1993;8:S597-S606.

9. Shinoda H, Adarnek G, Felix R, Fleisch H, Schenk R, Hagan P. Structure-activity relationships of various bisphosphonates. Calcif Tissue Int 1983;35:87-99.

10. Anderson C, Cape RDT, Crilly RG, Hodsman AB, Wolfe BMJ. Preliminary observation of a form of coherence therapy for osteoporosis. Calcif Tissue Int 1984;36:341-343.

11. Compston JE. The therapeutic use of bisphosphonates. Br Med J 1994;309:711-715.

12. Lowik CW, van der Pluijm G, van der Wee-Pals LJ, van Treslong-de Groot HB, Bijvoet OL. Migration and phenotypic transformation of osteoclast precursors into mature osteoclasts: the effect of a bisphosphonate. J Bone Miner Res 1988;3:185192.

13. Sahni M, Guenther HL, Fleisch H, Collin P, Martin TJ. Bisphosphonates act on rat bone resorption through the mediation of osteoblasts. J Clin Invest 1993;91:2004-2011.

14. Chambers TJ. Diphosphonates inhibit bone resorption by macrophages in vitro. J Pathol 1980;132:255-262.

15. Ito M, Amizuka N, Nakajima T, Ozawa H. Ultrastructural and cytochemical studies on cell death of osteoclasts induced by bisphosphonate treatment. Bone 1999;25:447-452.

16. Lin FH, Lin CC, Lu CM, Liu HC, Sun JS, Wang CY. Mechanical properties and histological evaluation of sintered $\beta-\mathrm{Ca}_{2} \mathrm{P}_{2} \mathrm{O}_{7}$ with $\mathrm{Na}_{4} \mathrm{P}_{2} \mathrm{O}_{7} \cdot 10 \mathrm{H}_{2} \mathrm{O}$ addition. Biomaterials 1995;16:793-802.

17. Sun JS, Tsuang YH, Liao CJ, Liu HC, Hang YS, Lin FH. The effects of calcium phosphates particles on the growth of osteoblast. J Biomed Mater Res 1997;37:324-334.

18. Harris ST, Gertz BJ, Genant HK, Eyre DR, Survill TT, Ventura JM, DeBrock J, Ricerca E, Chesnut CH III. The effect of short term treatment with alendronate on vertebral density and biochemical markers of bone remodeling in early postmenopausal women. J Clin Endocrinol Metab 1993;76:1399-1406.
19. Sun JS, Huang YC, Tsuang YH, Chen LT, Lin FH. Sintered dicalcium pyrophosphate increases bone mass in the ovariectomized rats. J Biomed Mater Res 2002;59:246-253.

20. Sun JS, Chang WHS, Hong RC, Hung TY, Lin FH, Liu HC Alveolar mononuclear cells can develop into multinucleated osteoclasts: An in vitro cell culture model. J Biomed Mater Res 2000;52:142-147.

21. Mosmann T. Rapid colorimetric assay for cellular growth and survival: Application to proliferation and cytotoxicity assay. J Immunol Methods 1983;65:55-63.

22. Sgonc R, Boeck G, Dietrich H, Gruber J, Recheis H, Wick G Simultaneous determination of cell surface antigens and apoptosis. Trends Genet 1994;10:41-42.

23. Schenk R, Eggli P, Fleiseb H, Rosini S. Quantitative morphometrir evaluation of the inhibitory activity of new aminobisphosphonates on bone resorplion in the rat. Calcif Tissue Int 1986;38:342-349.

24. Flanagan AM, Chambers TJ. Dichloromethylenebisphosphonate (C12MBP) inhibits bone resorption through injury to osteoclasts that resorb C12MBP-coated bone. Bone Miner 1989;6: 33-43.

25. Sato M, Grasser W, Endo N, Akins R, Simmons H, Thompson DD, Golub E, Rodan GA. Bisphosphonate action. Alendronate localization in rat bone and effects on osteoclast ultrastructure. J Clin Invest 1991;88:2095-2105.

26. Garnero P, Shih WJ, Gineyts E, Karpf DB, Delmas PD. Comparison of new biochemical markers of bone turnover in late postmenopausal osteoporotic women in response to alendronate treatment. J Clin Endocrinol Metab 1994:79:1693-1700.

27. Kerr JFR, Wyllie AH, Currie AR. Apoptosis: A basic biological phenomenon with wide-ranging implications in tissue kinetics. Br J Cancer 1972;26:239-257.

28. Oberhammer F, Fritsch G, Schmied M, Pavelka M, Printz D, Purchio T, Lassmann H, Schulte-Hermann R. Condensation of the chromatin at the membrane of an apoptotic nuclears is not associated with activation of an endonuclease. J Cell Sci 1993; 104:317-326.

29. Fleisch H. Bisphosphonates: Mechanisms of action. Endocrine Rev 1998;19:80-100.

30. Parfitt AM, Mundy GR, Roodman GD, Hughes DE, Boyce BF. A new model for the regulation of bone resorption, with particular reference to the effects of bisphosphonates. J Bone Miner Res 1996;11:150-159. 